\title{
A Pandeia: a arte de Educar para a Vida toda diante dos desafios de uma Pedagogia da Infância
}

Juliana Cristina Costa ${ }^{1}$

\section{Resumo}

Estuda as origens do pensamento filosófico ocidental sobre Educação, a partir da sociedade grega antiga, de base escravocrata. Destaca as diferentes etapas de formação da concepção grega de Educação ou Paideia e discute seus significados e desdobramentos. Aponta a Paideia como um ideal de educação plena, educar para a vida, como processo de formação humana. Estuda topicamente as etapas da organização da educação e da escola no Brasil. Analisa as políticas sociais e educacionais e explicita as características autoritárias e excludentes da sociedade e, por conseguinte, da escola no Brasil. Afirma suas características adultocêntricas e impositivas e aponta ser necessária uma superação das marcas e dos determinantes de natureza social e política para a construção ou para a emergência de práticas de reconhecimento da Criança e da Infância no Brasil. A prática pedagógica de acolhimento da Criança na escola necessita de superações de natureza filosófica e política dos estigmas das formações pedagógicas dominantes.

Palavras-chave: Educação. Criança. Infância. Paideia.

\section{Resumen}

Estudia los orígenes del pensamiento filosófico occidental sobre Educación, a partir de la sociedad griega antigua, de base esclavócrata. Destaca las diferentes etapas de formación de la concepción griega de Educación o Paideia y debate sus significados y desdoblamientos. Apunta a Paideia como un ideal de educación plena, educar para la vida, como proceso de formación humana. Estudia tópicamente las etapas de la organización de la educación y la escuela en Brasil. Analiza las políticas sociales y educativas y explicita las características autoritarias y excluyentes de la sociedad y, por consiguiente, de la escuela en Brasil. Afirma sus características adultocéntricas e impositivas y apunta que es necesaria una superación de las marcas y de los determinantes de naturaleza social y política para la construcción o emergencia de prácticas de reconocimiento del Niño y la Infancia en Brasil. La práctica pedagógica de acogida del Niño en la escuela necesita de superaciones de naturaleza filosófica y política de los estigmas de las formaciones pedagógicas dominantes.

Palabras-clave: Educación. Niño. Infancia. Paideia.

\footnotetext{
${ }^{1}$ Pesquisadora do Grupo de Estudos e Pesquisas PAIDEIA. E-mail: ju@unifeg.edu.br.
} 


\section{Introdução}

$\mathrm{O}$

presente trabalho trata de abordar a temática da busca da identidade da infância e da criança, numa abordagem histórica, social, política e filosófica, tendo como fundamentação os estudos realizados na disciplina "Metodologia da Filosofia e Educação", da linha de pesquisa "Filosofia e História da Educação", do grupo de pesquisa Paideia, coerente com os temas debatidos nesse Simpósio.

Para tratar da questão de uma educação para a vida toda, uma educação para a vida em sociedade como totalidade da formação humana, vamos buscar compreender as raízes da Educação desde os primórdios da Grécia, com seus ideais de formação do homem grego, da Paideia, que constitui o processo histórico e espiritual do homem, elaborando um IDEAL DE HUMANIDADE para a época, no âmbito da EDUCAÇÃO, da CULTURA e da POLÍTICA, utilizando o conhecimento e a ciência como fontes de uma evolução histórico-filosófica do saber crítico e emancipatório, que considera o sujeito cognoscente e politizado, partindo da história da Grécia Antiga - como o berço do saber - e ampliando-a com análise de outros autores que dedicaram-se à essa temática ao longo da história, tendo a educação como finalidade do conhecimento, posicionando-se contra a dominação ideológica, científica e política.

\section{A paideia ateniense e o pensamento inatista}

Considerando que a pergunta central que desencadeou as inquietações dos pensadores e da população da Grécia Antiga, foram geradas a partir da motivação de compreender a origem da vida e do mundo, encontramos as primeiras reflexões e explicações na MITOLOGIA, prevalecendo uma concepção transcendental e metafísica explicitada por meio dos mitos, especialmente o da criação, com uma educação fundamentada na crença, na religião e nos sentidos. $\mathrm{O}$ mito, portanto, 
contém em si um caráter normativo e educativo, constituindo um tesouro inesgotável de exemplos e modelos de ação, ideias e normas para a vida.

Nesse período mitológico da Grécia Antiga, Homero destaca-se como o grande educador grego, com suas obras épicas Ilíada e Odisseia, relatando a origem, o destino e a trajetória dos deuses. Para os antigos, a literatura, a arte, a poesia e a forma, como harmonia e composição, eram a expressão de toda a CULTURA elevada da vida em sociedade.

$\mathrm{Na}$ Paideia grega, o ideal de homem homérico, era aquele dotado de areté, característica de uma excelência nobre humana, um homem que tinha AGATHÓS (virtuoso e bom) e KALÓS (beleza), um homem com atos heroicos, defensor da cidade-estado ou pátria, educado, desde muito pequeno, para os grandes desafios.

A obra de Homero é inspirada, na sua totalidade, por um pensamento "fillosófico" relativo à natureza humana e às leis eternas que governam o mundo, contemplando todo o conhecimento à luz da essência das coisas, intimamente ligadas à origem da vida na poesia e nos cantos heroicos, à ideia de louvor, da glória e da imitação dos heróis. Assim, por meio dos poemas épicos, da literatura, Homero educava os homens para uma areté heroica e nobre. No entanto, era uma educação para a minoria aristocrática, elitista, de poder, técnica e privada.

Nesse contexto, encontramos ainda Hesíodo, uma outra referência de educador para o mesmo tempo, mas que valorizava o trabalho e o homem do campo, priorizando o trabalhador e não o herói, tendo o trabalho como ferramenta que dignifica o homem e contestando uma ética da minoria aristocrática para uma ética social do trabalho. Assim, o homem era educado num ambiente social, de acolhimento, diálogo, solidário, produtivo e coletivo. Em Hesíodo, destaca-se a areté social, por meio também da literatura, mas com a intervenção da justiça e da ética do trabalho no campo. Alicerça neste mundo natural e primitivo do trabalho, do homem mundano, a sua ideia de direito como fundamento de toda a vida social.

Nessa pedagogia metafísica, teológica e cosmológica, encontramos ainda a areté política de Tirteu, fundamentada numa literatura político- 
religiosa. Assim, a educação não era propriedade individual, mas pertencente por essência à comunidade e os poetas, músicos, filósofos, retóricos e oradores, eram os homens do Estado.

Os gregos e romanos fundamentaram então a educação como política e a finalidade do homem passou a ser viver em comunidade. No entanto, para isso, a vontade (instinto, irracionalidade) e a razão (logos, racionalidade) precisavam ser educadas na pólis. O fenômeno da Pólis tornou-se o espaço público onde ocorria o ato humano de reunir-se para deliberar coletivamente, sem prevalecer o individual e sim o consensual. Portanto, tornou-se um ato político que vem do conceito de espaço público e coletividade.

Ao surgir o ordenamento lógico, o LOGOS, surge também a FILOSOFIA científica e as reflexões para a explicação da origem da vida, utiliza-se de uma racionalidade, lógica e científica que nega os sentidos e a mitologia e tem como principal objeto a physis da natureza, uma ciência racional que discorre do problema da origem da vida, da matéria, e a busca uma compreensão por meio da investigação empírica sobre a essência do mundo. A prioridade da filosofia da natureza sobre a filosofia do espírito, revela o mais novo e profundo problema da vida, o problema do SER. Essa filosofia afirma que: "Só é verdade o que eu posso explicar por razões concludentes aquilo que o meu pensamento consegue justificar perante a si próprio.". Surge um conceito de VERDADE, que tem validade universal na explicação pelos fenômenos.

Nesse sentido, pode-se citar alguns filósofos pré-socráticos que buscavam o arché, o princípio fundamental da origem da vida, nos elementos da natureza, sejam eles, a terra, a água, o ar, o fogo, o número, o ápeiron. Para Anaximandro, o mundo é construído por rigorosas proporções matemáticas e foi ele o criador do primeiro mapa da Terra. Pitágoras, por exemplo, explicava o princípio da criação pelo número, com sua harmonia e composição. Para Tales de Mileto, era a água, fundamento de tudo, a umidade, o princípio do líquido. Heráclito dizia que a origem da vida era o fogo. 
Ao explicar a origem da vida pelos fenômenos da natureza, de forma racional, científica e lógica, o HOMEM se torna parte da totalidade da PHYSIS, como um ser em estrutura natural, amparado por uma história espiritual, interpretado de forma orgânica, com o princípio de totalidade.

Sócrates então considera o homem genérico como ser dotado de razão e sentimento e inicia-se um movimento educacional e cultural poderoso de uma areté baseada no saber. A ética, que se compreende por si próprio e portanto individual, cede espaço ao intelectual pelo alto apreço pelo saber e pela inteligência. Para isso, utiliza-se, além da literatura e da arte, a retórica, a gramática, a oratória e a dialética.

No período socrático, com Sócrates, Platão, Aristóteles e os sofistas, o centro das reflexões era a estruturação consciente da vida: adquirir consciência como uma grandeza para a posteridade.

Platão, com o "Mito da Caverna", faz uma análise crítica e racional sobre a forma de vida alienada dos sujeitos, tendo o mundo em que vivemos como uma simbologia da caverna, onde o conhecimento é representado pelo senso comum, por pré-conceitos, irracionalidade e de uma realidade refletida em sombras, mas não uma realidade absoluta, apenas de aparências e quanto mais essas projeções (sombras) se afastam dos sentidos, mais a verdade se revela. A vida fora desta caverna representa o conhecimento, a luz, a razão, o racional, a educação com a primeira verdade, o SER, a essência humana. À relação entre o mundo interior e exterior, chamamos de FILOSOFIA e EDUCAÇÃO como práticas de esclarecimento da verdade, de ensino em alto nível abstrato.

No entanto, para Platão, nem todos poderiam atingir esse grau do saber e compreendia a organização da comunidade em classes muito bem definidas, com uma estrutura social estamental: governantes, homens comuns (guerreiros, comerciantes...) e escravos. Classes engessadas e sem mobilidade social (ascensão social). Portanto, defendia um governo dos filósofos (pois eram considerados os melhores dos melhores), uma vez que governar é decidir e isso pressupõe conhecimento, o que contemplaria o bem, a vida, o belo, a natureza humana, a busca da felicidade plena. Para 
ele, a democracia era um estado de anarquia, porque as classes sociais têm suas características e nem todos têm sabedoria para a arte de governar, não são capazes de compreender e atuar na política. Assim ele volta a valorizar a areté aristocrática, "elitista", para poucos, propondo uma educação contemplativa política para as elites governantes (educação para o cérebro) e uma educação técnica para os dominados (educação para pés e mãos).

Já para os SOFISTAS, todos eram capazes de aprender e ensinar, assim, qualquer um poderia compreender o poder e exercê-lo. A principal ferramenta deles era a palavra, a oratória, o discurso, defendendo que não havia verdade absoluta, democratizando a política e a educação. Por esse motivo, foram perseguidos política e ideologicamente por Sócrates, Platão e Aristóteles, que os criticavam dizendo que seus discursos eram vazios, formas sem conteúdo, apenas ato de persuasão.

De uma forma geral, a formação do homem grego e a educação, como conjunto de práticas e teorias que permeavam o contexto da época, representavam a Paideia e, na totalidade grega, é possível identificar algumas paideias derivadas, todas representando uma aprendizagem para a vida inteira, iniciando com o nascimento e terminando com a morte, tendo o fim como completude.

\section{Superar os estigmas escravocratas e feudais.}

O conceito de Paideia torna-se uma prática social e de cultura cumulativa, um ideal civilizatório que humaniza e também condiciona pessoal, emocional e político-culturalmente - dando identidade à um grupo social e, por consequência, cobrando esse ideal de formação do homem.

Por um lado prevalece a tradição mítica, de base rural, derivada de Homero e Hesíodo, definida como educação arcaica, chamada também de paideia antiga, que consistia em buscar formar a aristocracia grega nos critérios de exaltação da coragem bélica e heroica, em elogiar a preparação para a guerra, para o cuidado da casa, treinar para o sucesso no exercício dos negócios particulares e no devotado e institucionalizado sacrifício aos deuses. Esta tradição da educação arcaica fundamenta-se na literatura mítica, centrada nas descrições épicas de Homero e Hesíodo, produzindo a legitimação de uma moral e de uma conduta política 
aristocrata, patriarcal, emasculada e segregacionista. (...) O conjunto de práticas de formação geral, para a Grécia aristocrática, era chamado genericamente de paideia. A Paideia representava o conjunto das práticas e das teorias que se reportavam a uma exigência fundamental da mentalidade grega, o desejo de forma e educar. $\mathrm{Na}$ Grécia arcaica, de tradição homérica, a educação dos jovens era a grande preocupação da nobreza. A educação ou Paideia configurava as lições dos adultos que preparavam os jovens para a aquisição da força, para a valentia, a destreza, a busca permanente da coragem, o estrito senso de dever e de honra que convêm aos guerreiros. Foi somente a partir do século $\mathrm{V}$ a.C., com o desenvolvimento da democracia, que as cidades passaram a formar seus cidadãos por meio de exercícios corporais, com as técnicas da ginástica e a ilustração da música, principalmente para a aquisição das habilidades da linguagem, da retórica e do pensamento ágil. (NUNES, 2017, p. 61)

Ainda buscando na filosofia e história da educação os fundamentos das mesmas para vida em comunidade e uma evolução/formação do homem, considerando as paideias modernas, encontramos as análises de Marx ao fazer suas críticas ao Estado. Para ele, o homem é fruto de suas condições materiais de sobrevivência e são essas condições de existência que determinam a consciência do homem. Assim, aqueles que têm propriedades/bens, são organizadores do mercado de trabalho e têm uma inserção diferente nos meios de produção, enquanto que os outros, que têm apenas a força física e mental, precisam se submeter ao trabalho para o outro, se vendendo por um salário e deixando de ser sujeito para ser objeto nesse sistema capitalista.

O trabalho torna-se toda a fonte de riqueza e produz uma desigualdade entre proprietários e não proprietários, entre ricos e pobres, entre capitalistas e trabalhadores.

Uma vez que o fundamento de acumulação do capital era produzir excedentes (produtos além do que necessitavam para a sobrevivência como base de troca e venda), os trabalhadores tinham suas jornadas de produção aumentadas, mas não recebiam nada mais por isso, ou adicionavam equipamentos e tecnologias para que os empregados produzissem mais em menos tempo de jornada de trabalho, assim, os proprietários enriqueciam, aumentando seus bens de capital (patrimônio) por meio da exploração do 
trabalho. O homem então se torna refém das relações de produção e capital, que derivam das condições materiais de sobrevivência e ditam os valores da consciência humana. O ser é substituído pelo ter.

Nessa mediação ideológica decifra-se o capitalismo. Para se enfrentar a materialidade do capitalismo é necessário o apoio de uma educação dialética e política, que faça a crítica desse sistema. Há que se desenvolver uma educação política e ideológica contra um mecanismo explorador, pois o capitalismo é um sistema onde o homem explora o próprio homem. Dessa forma, temos uma educação de base marxista, que define o materialismo histórico dialético.

O pensador húngaro Istvan Mészaros vai um pouco além e propõe uma "Educação para além do Capital", uma educação do homem omnilateral. A omnilateralidade é uma forma de resistência à mercadorização das consciências, humanizando o homem, ou seja, ampliando sua lateralidade horizontal como ser humano que se relaciona sem diferenças com outros seres humanos. O homem tem que ser educado de forma distinta da mercadoria. Nessa história inserimos as lutas da comunidade civil, dos movimentos de mulheres, dos movimentos de trabalhadores, que num contexto histórico, coloca a criança - objeto de estudo do presente trabalho - à margem da sociedade, principalmente a criança pobre, sem o devido respeito às especificidades da criança e de sua infância.

A proposta deste estudo é trazer as manifestações das crianças, que são próprias da naturalidade infantil, numa abordagem humanista, reflexiva e crítica, resgatando os estudos apresentados anteriormente para elucidar que as questões que moveram as grandes reflexões da humanidade desde a Grécia antiga ainda são as grandes questões das nossas crianças que brilhantemente "filosofam" sobre a vida e sobre o mundo.

Crianças sempre existiram, com suas manifestações curiosas e lúdicas, no entanto, o tema torna-se desafiador pois é carregado de improvisações do senso comum, perdurando a incompreensão dessa etapa da vida que foi e ainda é tratada com uma visão adultocêntrica da infância, 
inculcando nas crianças um ideal da vida adulta, antecipando fases e tornando obscuro o que é intrínseco e próprio da constituição do que é ser criança.

O caráter negativo e disciplinador da educação na primeira infância, ainda guarda grandes resquícios autoritários e restritivos que precisam ser superados com atitudes emancipatórias, de maneira humanizada e socialmente educativa.

\begin{abstract}
A condição da criança num país marcado por tantas contradições autoritárias, oriundas de sua tradição colonial e sua trajetória de dependência cultural e política, própria de dependências e estigmas culturais derivados de centros civilizatórios inspirados no imaginário medieval e colonial, bem como nas concepções mais retrógradas sobre a mesmanão é tarefa fácil de ser produzida a contento. Somente agora, no limiar da década de 1990, vimos construir um núcleo jurídico, resultado de uma longa empreitada de debates e heroicas apologias da cidadania da criança, consubstanciada no Estatuto da Criança e do Adolescente, promulgado em 1990. (NUNES, 2006, p. 2-3)
\end{abstract}

Desde o período colonial, em que a infância era tratada de acordo com as determinações de Portugal, as crianças índias eram conduzidas a obedecer às normas e costumes cristãos, negando a própria cultura. Usando as crianças, inculcando-lhes medo do inferno, importância do casamento monogâmico, ideia do pecado, os jesuítas pretendiam converter também os adultos. Caso houvesse resistência na catequização, os "soldados de Cristo", como eram chamados os jesuítas, podiam utilizar a força em nome da "guerra justa".

Historicamente, o abandono de crianças foi frequente até meados do século XIX. Nas classes média e alta, os filhos fora do casamento, segundo a moral cristã, eram frutos do pecado e, por isso, já nasciam predestinados ao abandono. Podemos entender a condição da criança como decorrente de uma determinada formação econômica, cultural e política. Numa sociedade escravocrata, baseada em relações de exploração e de dominação, não há como encontrar valores que reconheçam a criança e a infância. Nos períodos políticos posteriores prevaleceu o mesmo sentido, no Império e da emergente República. 
Com a abertura política do séc. XX, um novo quadro começa a ser desenhado e os juízes perdem poder de decisão sobre os menores. Entra em cena a sociedade civil que não aceita passivamente a estatística de que metade do contingente de 0 a 17 anos encontra-se em "situação irregular" e lançam um amplo movimento social, com apoio da Igreja e de progressistas do Governo, reivindicando os direitos de cidadania para crianças e adolescentes.

Esse movimento conseguiu inscrever sua proposta na Constituição de 1988, sob a forma do artigo 227, que manda assegurar, com absoluta prioridade, os direitos de crianças e adolescentes, incumbindo desse dever a família, a sociedade e o Estado, aos quais cabe, igualmente, protegê-las contra qualquer forma de abuso. (PILOTTI \& RIZZINI, 1995)

Ainda hoje, o "Estatuto da Criança e do Adolescente" é o documento que representa um novo paradigma jurídico, político e administrativo no que se refere à questão da infância e juventude em nosso país, considerando o atendimento desta população como parte das políticas sociais.

Mas, considerando toda a demora de implantação de novos sistemas, o despreparo dos profissionais, a falta de verba, os desvios financeiros, a ideia ainda não reflete o sucesso dessa iniciativa. Assim, apesar dos avanços, considerando até mesmo o Estatuto da Criança e do Adolescente, em termo de ação eficiente à infância, praticamente não saímos do lugar.

Este não é um quadro geral das crianças do Brasil, uma vez que a infância dos pequenos burgueses e aristocráticos foi muito mais reconhecida por suas famílias, o que se pode constatar nos retratos de família burguesa da época, nos tratados de medicina e de educação, na remodelação do espaço doméstico, utilização de novos métodos pedagógicos, brinquedos atraentes, enfim, apesar de todas as disparidades entre ricos e pobres, podemos dizer que todos foram crianças, mas não é verdade que todos tiveram infância.

É preciso considerar a infância como uma condição da criança. $\mathrm{O}$ conjunto das experiências vividas por elas em diferentes lugares históricos, geográficos e sociais é muito mais do que uma representação dos adultos sobre esta fase da vida. É preciso conhecer as representações de infância e considerar as crianças concretas, localizálas nas relações sociais, etc, reconhecê-las como 
produtoras da história. Desse ponto de vista, torna-se difícil afirmar que uma determinada criança teve ou não teve infância. Seria melhor perguntar como é, ou como foi, sua infância. Porque geralmente se associa o não ter infância a uma característica das crianças pobres. Mas com isso, o significado de infância se torna imediatamente abstrato e essas pessoas, excluídas de direitos básicos, receberão a culpa de não terem sido as crianças que foram, da forma como foi possível, irreversivelmente. $\mathrm{O}$ que os excluídos não têm é o que a sociedade lhes sonega. A vida, sofrida, enquanto dura, ao menos, é algo que lhes pertence. (KUHLMANN JUNIOR, 1998).

De uma forma geral, na busca das possibilidades de uma efetiva compreensão científica e racional da infância e de suas especificidades, muitos autores, das mais variadas áreas do conhecimento, passaram a pesquisar, analisar e conceituar a infância, redimensionando os estudos, apresentando novas descobertas e reflexões sobre o tema, complementando pesquisas anteriores e avançando na determinação de uma identidade da infância.

Como análise histórica e social, não poderíamos deixar de referenciar um dos precursores sobre as pesquisas dessa temática, J.J. Rousseau:

\begin{abstract}
Afirma-se cada vez mais a tese de que a pedagogia moderna redescobriu a infância, a partir de J. J. Rousseau, filósofo francês que viveu de 1712 a 1778 , na Europa iluminista moderna. O seu livro denominado Emilio ou da Educação, publicado em 1762, é tido como um marco inaugural novo e original na concepção ocidental moderna sobre a criança, com seu naturalismo pedagógico como suporte e firme determinação política de afirmar ser a educação uma proposição singular de constantes práticas de liberdade. (NUNES, 2006, p. 4)
\end{abstract}

Rousseau interpreta a infância não como uma via de acesso e como um período de preparação para a vida adulta, mas que essencialmente a infância tenha um valor em si mesma e que, respeitando suas características de ser natural, deveria também recepcionar uma educação baseada em ações naturais, resultado do livre exercício das próprias capacidades infantis, ressaltando o que a própria criança é capaz de saber. Esta concepção rousseaniana leva-nos a um desafio de refletirmos sobre as efetivas 
capacidades dos saberes característicos da própria infância, frente aos saberes condicionados e introjetados pelo adulto que nega às crianças sua própria identidade infantil.

\section{Considerações Finais}

As discussões em torno da infância encontram também nos estudos de Phillipe Àries (1981), elementos que mostram que a "descoberta" da infância, ou seja, a "consciência" da particularidade infantil que a diferencia do adulto, teve seu início quando a posição da criança emerge na história da arte e da iconografia do século XV por meio de figuras de crianças representadas como anjos. Logo em seguida, segundo ele, a escola assume a aprendizagem como meio de educação e a criança deixa de ser misturada aos adultos e passa a viver uma espécie de quarentena na escola. Isso aconteceu primeiramente nas camadas mais altas da sociedade e o sentimento de infância ia do nobre para o pobre.

Numa análise ainda mais aprofundada, de caráter filosófico, histórico e político, encontramos em Habermas, um dos maiores filósofos alemães do séc. XX, grande educador da atualidade e considerado um dos maiores herdeiros da escola de Frankfurt, um alerta sobre a importância da Universidade e, aqui com o nosso destaque, enfatizo a formação de professores, tendo esta como uma esfera pública especializada, que deve compreender a educação na esteira do esclarecimento onde educar é emancipar. É preciso que na educação o aluno, aqui com o destaque para o docente e pesquisador em formação, se liberte de seus medos, tendo liberdade para emancipar-se, fazendo com que o ator social, na esfera pública e da sociedade, possa atuar com esclarecimento real e concreto da história (não no modo burguês).

A construção dos saberes para Habermas tem uma dupla perspectiva, não é só epistemológica (puro conhecimento, pura cognição), mas também identitária (o conhecimento consigo mesmo e com o outro). O saber em Habermas não é simplesmente cognitivo é, além disso, um saber estético (inclusive com a estética da fala), saber autêntico e saber normativo. O saber 
é cognição, sem dúvidas, mas há uma esteticidade, principalmente da fala/linguagem, como um saber autêntico e normativo das relações humanas. O saber é uma construção, principalmente construção simbólica por meio da linguagem/linguística, sendo que o conhecimento é um processo.

No cenário educativo, a relação ensino-aprendizagem precisa estar centrada nos atores que fazem as estruturas educativas, sendo que todos têm os mesmos direitos de fala, com um conhecimento socialmente partilhado e reconhecido. A criança ou o jovem deixa então de ser um objeto, um mero receptáculo. Professor e estudante se reconhecem com atores e autores instituídos.

Habermas propõe que os atores sejam reconhecidos naquilo que pensam, que falam e naquilo que escutam e isso requer uma sociedade mais evoluída, democraticamente falando, superando uma sociedade autoritária. Habermas propõe uma razão educativa, comunicativa, partilhada, razão esclarecida e sujeito emancipado. Esclarece que o Estado colonizou a vida em sociedade e a luta contra essa condição, são as organizações da comunidade em busca de seus direitos (conselhos, movimentos...) por meio do uso racional e identitário da linguagem e do consenso.

Compartilhando com Habermas sobre o conceito de Universidade como esfera pública especializada, conclamamos os docentes, pesquisadores, especialistas das mais diversas áreas, educadores em geral, a exercer um papel crítico junto à cultura, à sociedade e junto ao estado, como órgão regulador dessas relações, sendo um escola das linguagens, e que, na prática escolar, seja na Educação Básica ou Superior, seja incluído o teatro, a arte, o cinema e todas as ciências, num amplo leque de saberes.

Dessa forma, teremos grandes possibilidades de cuidar e educar nossas crianças, respeitando suas especificidades, garantindo à elas a exploração de suas linguagens e ampliação das mesmas, fazendo uso de seus questionamentos sobre a vida e o mundo, descortinando o conhecimento na ação sobre os objetos e o mundo que a cerca, refletindo sobre suas relações com o outro, compreendendo na prática a diversidade 
que a rodeia e construindo sua identidade de forma subjetiva, histórica e social, dando-lhes direito à infância de qualidade, com base na equidade.

Esse trabalho buscou, de forma ainda sucinta, elucidar a urgência de requerer uma sólida concepção científica e filosófica sobre a questão da criança e da infância, superando a superficialidade e o senso comum que permeiam a temática e consolidando a arte de educar para a vida toda, retomando a amplitude e dinamicidade política do conceito de Paideia.

\section{Referências}

ÀRIES, P. História Social da Criança e da Família. R. J.: Zahar Editores, 1981.

BRASIL. Constituição da República Federativa do Brasil. São Paulo: Imprensa Oficial do Estado, 1988.

BRASIL. Estatuto da Criança e do Adolescente. Lei no 8.069/90, de 13 de julho de 1990. São Paulo, CBIA SP.

NUNES, C. e SILVA, Edna. Educação Sexual da Criança - Polêmicas do nosso tempo. Campinas, SP: Autores Associados, 2006.

NUNES, C. Platão e a dialética entre a filosofia do amor e o amor à filosofia. Campinas, SP: Librium Editora e Editora Brasílica, 2017.

KRAMER, Sônia. A política do pré-escolar no Brasil: a arte do disfarce. 5. ed. São Paulo: Cortez, 1992.

KRAMER, Sônia. e ABRAMOVAY, M. "O Rei está nu”: um debate sobre as funções da pré-escola. In: Cadernos Cedes, n. 9. UNICAMP, 1991.

KUHLMANN JR, Moysés. Infância e Educação Infantil: uma abordagem histórica. Porto Alegre: Mediação, 1998. 
PILOTTT, Francisco e RIZZINI, Irene (orgs.). A Arte de governar crianças: a história das políticas sociais, da legislação e da assistência à infância no Brasil. Rio de Janeiro: Instituto Interamericano Del Nino, Editora Universitária Santa Úrsula, Amais Livraria e Editora, 1995.

SOUZA, Solange Jobim e KRAMER, Sonia. Educação ou tutela? A criança de 0 a 6 anos. Campinas: UNICAMP, 1997. 